\title{
The Relationship of Hair Zinc Concentrations to Height, Weight, Age, and Sex in the Normal Population
}

\author{
PHILIP S. GENTILE, ${ }^{(24)}$ MARK J. TRENTALANGE, AND MARY COLEMAN
}

Department of Chemistry, Fordham University, Bronx, New York [P. S. G.]; Department of Psychology, Fordham University, Bronx, New York [M. J. T.]; and Children's Brain Research Clinic, Washington, D. C., USA [M. C.]

The purpose of this project is to further the use of hair trace element concentrations as a diagnostic/research tool. Feces and urine are poor indicators of body stores of trace elements. Blood may be used in certain situations, but is subject to the operation of homeostatic mechanisms which either vary widely over short periods of time or act to keep variables constant. Scalp hair is not only a more reliable indicator of long-term internal milieu, but may be more easily collected (i.e., by untrained personnel), shipped, and prepared for analysis than blood or tissue samples. Hair also may be used to detect a wide range of trace elements Zinc, which comprises the largest concentration of the trace metals in hair, is especially well suited for this type of measuremen because it is relatively evenly distributed along the hair shaft and insensitive to spurious environmental variations $(4,13,23)$.

A pilot study (6) indicated that a number of growth-related physical measures may be correlated with hair zinc concentrations $(\mathrm{Zn})$ in the normal population. Studies of animals $(2,18,19)$, as well as human dwarf or growth-retarded samples $(7,11,15,17$, 20-22) indicate that zinc deficiency inhibits growth. This trend appears to be reversible, as evidenced by the gains in growthrelated variables upon alleviation of the zinc-deficient state. Yet, information concerning the relationship of the major physical measures: height, weight, age, and sex, to hair $\mathrm{Zn}$ in the normal population is either missing (as in the cases of weight and height) or confused (as in the cases of sex and age). The previously mentioned pilot study brought out the need for insight into the relationships of all these variables in order to be able to compare various sample groups. Although weight and height gains have been noted in $\mathbf{Z n}$-deficient people undergoing $\mathbf{Z n}$ supplementation, no study has attempted to quantify the relationships of these variables with hair $\mathrm{Zn}$ in a normal sample. It is highly likely that growth-related trends may be sex or age dependent.

Age and sex are most frequently the subject of major experimental inquiries $(1,3,5,8,10,14,16)$. Those studies which comment on sex differences reveal conflicting results. Klevay (10) found no sex differences, whereas, Creason et al. (3) found sex differences for children under 15 years, but not for adults. In general, $\mathrm{Zn}$ concentrations for females are slightly higher; however, this difference is not evidenced in every study (23).

There is also confusion in the literature concerning the nature of the relationship of hair $\mathrm{Zn}$ to age. Several researchers have noted high $\mathrm{Zn}$ values during the period immediately after birth $(8,10)$ which have been attributed to a residual (elevated) $\mathrm{Zn}$ contribution from the mother. A period of decline then follows, the length of which ranges from 3 months (8) to 10 years (10). All researchers have found an increase in hair $\mathrm{Zn}$ values in childhood and either a leveling off or a gradual decline in adulthood. The inflection age for this change varies considerably from about 12 (14) to about 20 years old $(5,8,10)$. Valković $(23)$ concludes from a comparison of data from Klevay (10), Hambidge et al. (8), and Strain et al. (22),
Therefore, it appears that levels of zinc in hair are not directly related to age, and it is possible that levels at any age reflect zinc nutritional status (p. 118).

This conclusion seems a bit premature in the absence of information concerning growth-related variables. It is suggested that the combined influence of height, weight, age, and sex must be quantified and removed before a reflection of relative $\mathrm{Zn}$ nutritional status may be obtained from hair analysis. At this stage of research, quantification should assume the form of correlational studies in particular. Those variables which are found to have strong relationships may be used to develop a predictive equation for hair $\mathrm{Zn}$ concentrations. Although their conclusions differ slightly from those of other investigators, the interesting application of regression techniques by Petering et al. (14) prompted the approach to data analysis utilized in this study.

\section{MATERIALS AND METHODS}

Concentrations of zinc in the hair of normal children and parents were measured by atomic absorption spectrophotometry (AAS). Hair samples were collected very close to the scalp with a stainless steel scissors. The sample preparation technique of Harrison et al. (9), recommended by the AAS manufacturer (PerkinElmer model 303), was slightly modified. Each sample was washed in a nonionic detergent (7X-o-matic; Linbro Scientific, Inc.), rinsed with deionized water, and dried overnight in an oven at $110^{\circ} \mathrm{C}$. About $0.1 \mathrm{~g}$ of hair was weighed, ashed in $70 \%$ nitric acid (Baker Analyzed Reagent), and evaporated to dryness by slow heating. The residue was redissolved in $25 \mathrm{ml}$ of $10 \%$ nitric acid and transferred to volumetric flasks. Standards were prepared from aliquots of certified spectroscopic grade AAS reference solution (Fisher Scientific Co., Inc.). Deionized water was used for all dilutions. Standards, 10\% nitric acid correction blanks, and samples were analyzed on the AAS, and the amount of $\mathrm{Zn}(\mu \mathrm{g} / \mathrm{g})$ per gram of hair was computed. With this method, sample reproducibility was very good. Repeated determinations of 40 samples, in addition to the current group (total, $n=89$ ), on different days yielded a Pearson correlation coefficient of $0.9925(P<0.00001)$ and a standard error of estimate of $6.9976 \mu \mathrm{g} / \mathrm{g}$.

Additional subject data concerning height, weight, age, and sex, were coded for analysis. Statistical procedures were done on a DEC-20 computer at Fordham University, using SPSS (Statistical Package for the Social Sciences) programs (12).

\section{SUBJECTS}

Twenty-six white males and 23 white females, ranging in age from 15 months to 63 years, participated in this study. Most were apparently normal (presenting no obvious or stated medical problems) friends or relatives of patients seen at the Children's Brain Research Clinic (Washington, D. C.). Many were serving as 
controls for a concurrent study of hair $\mathrm{Zn}$ values in Down's syndrome children. A few of the experimenters and their relatives also participated. All subjects agreed to the requirements of this study after being informed of its purpose.

Most of the subjects fell within the normal 95 percentile limits for their age-appropriate weights and heights. Only 5 of 49 subjects had weights beyond the 95 th percentile for their age. Of these, only two fell outside the 99 th percentile for weight. Three subjects were found to have heights above the 95th percentile for their age group, but no subject had a height beyond the 99th percentile. In all, the sample was reasonably representative of the normal population for weight and height. Missing data accounts for variable sample sizes in the reported statistical results.

\section{RESULTS}

Descriptive statistics are tabled for inspection. Tables 1 and 2 list sample size $(N)$, mean, standard deviation, and range for each variable. In addition to providing 95\% confidence intervals for hair $\mathrm{Zn}$ concentrations, Table 1 subdivides the sample by sex and by age (children, under 240 months; adults, over 240 months).

An examination of the data plots for $\mathrm{Zn}$, height, weight, and age indicates that these variables all intercorrelate in normals to some degree. Although the values of these intercorrelations are slightly different for each sex, comparative testing of correlation coefficients (using Fisher's $z$ transformation) did not reveal any significant sex differences in either childhood or adulthood. Therefore, coefficients are presented in Table 3 without regard for sex.

It was found that the relationship of age to $\mathrm{Zn}$ is roughly linear from early childhood [although probably not from immediately preceeding birth; (8)] to about 240 months. The coefficients for adults indicate that age bears little or no relationship to hair $\mathrm{Zn}$ after about 240 months (about 21 years). On the other hand, the correlation of $\mathrm{Zn}$ with body weight persists after age 20 to 21 years in this normal sample, albeit with a meaningful change in slope (from positive to negative). Height follows the same basic trends as weight with hair $\mathrm{Zn}$ although, the relationship becomes less pronounced in adulthood.

Rarely is it convenient (or possible) to match sample groups on a number of physical characteristics. Therefore, the next step in

Table 1. Descriptive statistics for zinc in hair (in $\mu \mathrm{g} / \mathrm{g}$ )

\begin{tabular}{|c|c|c|c|c|c|}
\hline Sample & $(N)$ & Mean & S.D. & Range & $\begin{array}{c} \pm 95 \% \\
\text { confidence } \\
\text { interval }\end{array}$ \\
\hline \multicolumn{6}{|c|}{ Children (under 240 months) } \\
\hline Male & (19) & 141.5 & 58.0 & $31.7-229.7$ & \pm 27.9 \\
\hline Female & (15) & 151.1 & 61.7 & $25.9-222.9$ & \pm 34.2 \\
\hline Total & (34) & 145.7 & 58.9 & $25.9-229.7$ & \pm 20.6 \\
\hline \multicolumn{6}{|c|}{ Adults (over 240 months) } \\
\hline Male & (7) & 159.3 & 25.3 & $120.7-194.8$ & \pm 23.4 \\
\hline Female & (8) & 190.0 & 43.9 & 103.3-235.7 & \pm 36.7 \\
\hline Total & (15) & 175.7 & 38.6 & 103.3-235.7 & \pm 21.4 \\
\hline
\end{tabular}

Table 2. Descriptive statistics for physical attributes

\begin{tabular}{|c|c|c|c|c|}
\hline Variable & $(N)$ & Mean & S.D. & Range \\
\hline \multicolumn{5}{|c|}{ Children (under 240 months) } \\
\hline Age (months) & (34) & 113.97 & 70.6 & $15.0-240.0$ \\
\hline Weight (kg) & (33) & 32.97 & 20.9 & $8.2-86.2$ \\
\hline Height (cm) & (23) & 133.38 & 37.3 & $71.1-185.4$ \\
\hline \multicolumn{5}{|c|}{ Adults (over 240 months) } \\
\hline Age (months) & (15) & 409.53 & 166.3 & $270.0-756.0$ \\
\hline Weight (kg) & (14) & 64.70 & 15.5 & $37.2-104.2$ \\
\hline Height (cm) & (13) & 166.88 & 8.0 & $157.5-181.6$ \\
\hline
\end{tabular}

this analysis was to determine how "predictable" hair $\mathrm{Zn}$ was on the basis of these few easily obtained measures (i.e., height, weight, age, and sex). Inasmuch as no reliable norms exist for such a prediction, a multiple linear regression procedure was used to generate an equation to predict hair $\mathrm{Zn}$ concentrations based on a person's height, weight, age, and sex.

The regression equations, derived from subjects with complete data records, are presented in Table 4. It seems that the variables assume slightly different relative importance in the prediction of hair $\mathrm{Zn}$ values for each sex. The amount of variance in $\mathrm{Zn}$ concentration due to height, weight, and age appears to be quite considerable in children: males, $46.9 \%$; females, $80.0 \%$; and combined, $47.7 \%$ (multiple $r^{2}$ values). For the adult sample, linear regression of these three variables accounted for: males, $4.5 \%$; females, $61.6 \%$; and combined, $24.6 \%$ of the variation in $\mathrm{Zn}$ values. Although caution must be exercised in any interpretation of these data due to the small adult sample size, it is maintained that given

Table 3. Correlation matrix

\begin{tabular}{|c|c|c|c|c|}
\hline & $\mathrm{Zn}$ & Age & Weight & Height \\
\hline \multicolumn{5}{|c|}{ Adults (upper triangle) } \\
\hline \multicolumn{5}{|l|}{$\mathrm{Zn}$} \\
\hline$N^{1}$ & & 15 & 14 & 13 \\
\hline$r$ & & -0.182 & -0.464 & -0.336 \\
\hline$P$ & & n.s. & 0.047 & n.s. \\
\hline
\end{tabular}

Children (lower triangle)

Age

$N \quad 34$

$r \quad 0.695$

$P$

0.695

Weight

$N$

$33 \quad 33$

$r$

0.613

$0.00008-0.0000$

14

0.286

13

0.0000

n.s.

Height

$\begin{array}{llll}N & 23 & 23 & 23 \\ r & 0.666 & 0.939 & 0.931 \\ P & 0.00026 & 0.00001 & 0.00001\end{array}$

' $N$, number of subjects in sample; $r$, Pearson correlation coefficient; $P$, probability associated with a given $r$; n.s., not significant.

Table 4. Regression equations

\begin{tabular}{lccc}
\hline Sample & $N^{\prime}$ & Multiple $r$ & Multiple $r^{2}$ \\
\hline Children & & \\
Total & 23 & 0.691 & 0.477 \\
[Equation: $P=$ & Age $(0.347)+$ HT $(0.394)+$ WT & $(-0.252)+67.326]$ \\
Male & 15 & 0.685 & 0.469 \\
[Equation: $P=$ HT $(0.867)+$ Age & $(0.067)+19.147]$ \\
Female & 8 & 0.895 & 0.800 \\
[Equation: $P=$ HT $(2.206)+$ WT $(-8.018)+$ Age $(1.083)+2.935]$
\end{tabular}

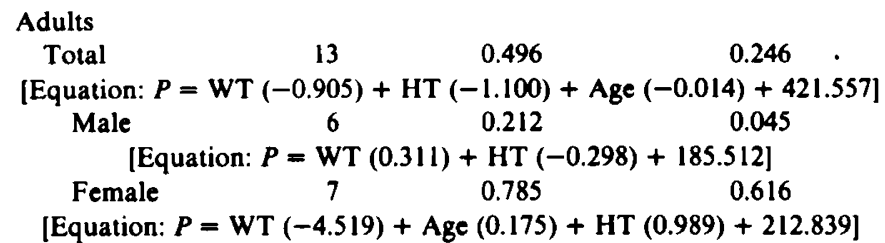

$1 N$, number of subjects in sample; $r$, multiple Pearson correlation coefficient; $P$, zinc value predicted from the regression equation (in $\mu \mathrm{g} / \mathrm{g}$ ), for hair samples; age, age of the subject (in months); HT, height of the subject (in $\mathrm{cm}$ ); WT, weight of the subject (in kilograms). 
the required information, hair $\mathrm{Zn}$ in females may be generally more predictable than in males.

Using the predicted normal $\mathrm{Zn}$ values, the normality of other clinical samples may be tested. Because the equations were generated from this sample, the cumulative differences of individual $\mathrm{Zn}$ values from their predicted values should be close to zero. For another, nonnormal sample, the deviations of actual from predicted $\mathrm{Zn}$ values should be larger. These group deviations (residuals) may be compared using conventional $t$ tests. Although the application of this technique is intended for clinical samples, this procedure was used internally to search for sex differences.

Table 5 summarizes a futile search for sex differences in these samples. Both raw score values and those transformed by their respective regression equations (i.e., residual values) were compared using the $t$ test for means and the $F$ test for sample variances. Although females appear to have slightly higher hair $\mathrm{Zn}$ concentrations, no significant differences between the sexes in means or variances were found in either the raw score or residual analyses.

\section{DISCUSSION}

Comparisons of results demonstrate the hair $\mathrm{Zn}$ values in this study to be reasonably within the absolute ranges of most other published reports [see review by Valković (23)]. Figures 1 to 3 clearly show the linear trends in the data for children. Because no sex differences were found, the data are pooled across this category. In general, all these graphs exhibit similar trends. The information in the graph of age versus hair $\mathrm{Zn}$ agrees roughly with Klevay (10), Hambidge et al. (8), and Eatough et al. (5). Regarding mean values, a slight decline may possibly be discerned in early childhood, blending quickly into an approximately linear trend and peaking at a high value at about 20 to 21 years. This precise inflection point may vary with sex and cultural milieu. Although adult values are not shown, a decrease in hair $\mathrm{Zn}$ values is noted in later years.

The most important conclusion from these analyses is that height and weight both bear as significant, if not more significant, a correlation to $\mathrm{Zn}$ nutriture (as assessed by hair $\mathrm{Zn}$ ) as age does. It may be that in the three previously cited studies $(5,8,10)$, the age correlation is largely an artifact of the growth-dependent $\mathrm{Zn}$ / height and $\mathrm{Zn} /$ weight relationships. Examination of the age trends in this and the previously mentioned studies shows increases and plateaus corresponding to normal growth patterns. Logically, it makes considerably more sense to examine $\mathrm{Zn}$ nutritional status with respect to factors such as height and weight than to age alone.

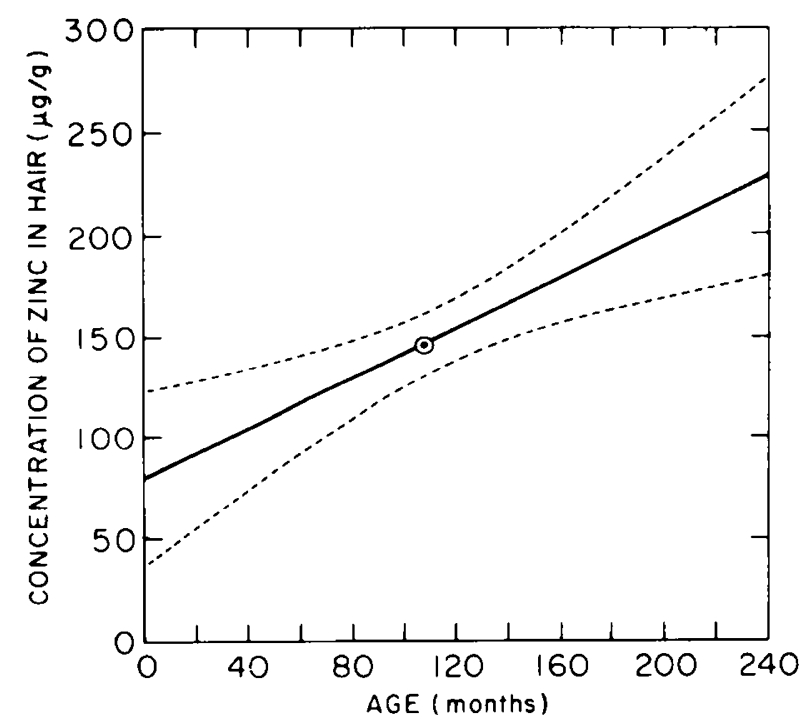

Fig. 1. Linear regression line with $95 \%$ confidence limits for zinc concentrations in hair (in $\mu \mathrm{g} / \mathrm{g}$ ) and age (in months), for children (under 240 months). $\odot$, grand means of hair zinc and age. $(N=34)$.

Table 5. $t$ tests for sex differences

\begin{tabular}{|c|c|c|c|c|c|c|c|c|}
\hline \multirow[b]{2}{*}{ Group } & \multirow[b]{2}{*}{$(N)^{1}$} & \multirow[b]{2}{*}{ Mean } & \multirow[b]{2}{*}{ S.D. } & \multirow[b]{2}{*}{$F$} & \multirow[b]{2}{*}{$\begin{array}{c}2 \text {-tail } \\
\text { probability }\end{array}$} & \multicolumn{3}{|c|}{ Pooled variance estimate } \\
\hline & & & & & & $t$ & df & $\begin{array}{c}\text { 2-tailed } \\
\text { probability }\end{array}$ \\
\hline \multicolumn{9}{|c|}{ Children (under 240 months) } \\
\hline \multicolumn{9}{|c|}{ Raw score hair zinc concentrations ( $\mu \mathrm{g} / \mathrm{g}$ hair) } \\
\hline Male & (15) & 148.17 & 53.44 & 1.02 & 1.000 & -0.50 & 21 & 0.622 \\
\hline Female & $(8)$ & 159.81 & 52.82 & & & & & \\
\hline \multicolumn{9}{|c|}{ Residual values (pooled regression equation) } \\
\hline Male & (15) & -6.21 & 39.59 & 1.39 & 0.682 & -1.08 & 21 & 0.291 \\
\hline Female & $(8)$ & 11.65 & 33.56 & & & & & \\
\hline \multicolumn{9}{|c|}{ Residual values (separate regression equations) } \\
\hline Male & (15) & 0.00 & 38.93 & 2.72 & 0.188 & 0.00 & 21 & 1.000 \\
\hline Female & $(8)$ & -0.00 & 23.62 & & & & & \\
\hline \multicolumn{9}{|c|}{ Adults (over 240 months) } \\
\hline \multicolumn{9}{|c|}{ Raw score hair zinc concentrations (in $\mu \mathrm{g} / \mathrm{g}$ hair) } \\
\hline Male & (6) & 157.42 & 27.18 & 2.90 & 0.263 & -1.36 & 11 & 0.202 \\
\hline Female & (7) & 186.69 & 46.29 & & & & & \\
\hline \multicolumn{9}{|c|}{ Residual values (pooled regression equation) } \\
\hline Male & (6) & -3.16 & 33.52 & 1.31 & 0.785 & -0.29 & 11 & 0.776 \\
\hline Female & (7) & 2.71 & 38.36 & & & & & \\
\hline \multicolumn{9}{|c|}{ Residual values (separate regression equations) } \\
\hline Male & (6) & 0.00 & 26.56 & 1.17 & 0.886 & -0.12 & 11 & 0.905 \\
\hline Female & (7) & 1.89 & 28.67 & & & & & \\
\hline
\end{tabular}

' $N$, number of subjects in sample; df, degrees of freedom. 


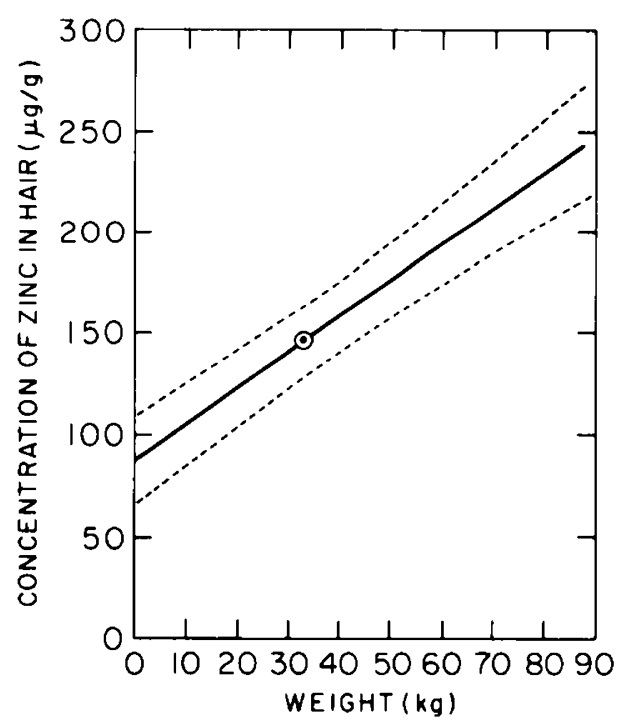

Fig. 2. Linear regression line with $95 \%$ confidence limits for hair zinc concentrations (in $\mu \mathrm{g} / \mathrm{g}$ ) and weight (in $\mathrm{kg}$ ) for children (under 240 months). $\odot$, grand means of hair zinc and weight. $(N=33)$.

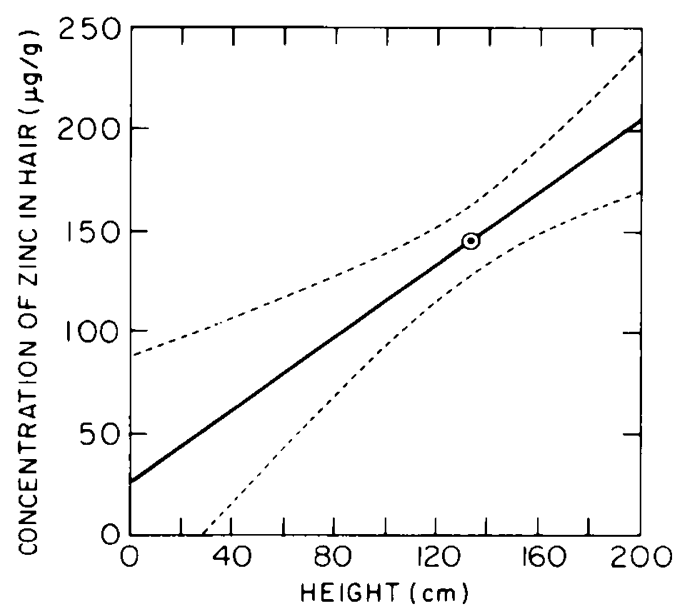

Fig. 3. Linear regression line with $95 \%$ confidence limits for hair zinc concentrations (in $\mu \mathrm{g} / \mathrm{g}$ ) and height (in $\mathrm{cm}$ ) for children (under 240 months). $\odot$, grand means of hair zinc and height. $(N=23)$.

\section{CONCLUSIONS}

There are several important implications of these findings. (1) For the first time, hair $\mathrm{Zn}$ was found to correlate with height, weight, and age in a normative sample. (2) In many cases, research must be tempered (or precluded) by these relationships (e.g., as in certain clinical populations such as geriatric patients, obesity cases, samples which vary widely in age, or samples which span the transition into adulthood). (3) It was noted earlier that frequently it is impracticable to match subjects for several variables. It is a significant ability to be able to eliminate major sources of variation, especially due to such easily observable and quantifiable measures as were embraced in this study. This practice should help to sharpen the discriminability of hair as biopsy material. (4) Although its precision limits its usefulness for individual assessments, sophisticated use makes hair analysis an ideal tool for the identification of group differences and of the associated metabolic pathways. At least two applications of these results are obvious. First is the comparison of a control group to a clinical sample using both raw score and transformed values. A regression equation would be developed from the control group and applied to both the control and clinical samples. The deviations from the predicted $\mathrm{Zn}$ values in hair should be greater for the clinical group than the control group.

Second, correlation matrices of sufficient sample size could be factor analyzed (especially Principal Component Analysis) as a means of simplifying a large amount of intricately related data. Research decisions and theoretical considerations may depend upon clues provided by this type of analysis. The identification of certain trends may be the inroad to the facets of $\mathrm{Zn}$ nutrition which are reflected in hair.

\section{SUMMARY}

Hair samples from forty-nine normal individuals (both children and adults) were assessed for concentrations of zinc. Pearson correlation coefficients were computed between zinc values and the variables: height, weight, and age (see Table 3 ). In children (under 240 months), all these relationships were linear, positive, and statistically significant. A linear regression equation using all these variables was found to account for $47.7 \%$ of the variance in hair zinc concentrations. In adults (over 240 months), the correlation coefficients between hair zinc and height, weight, and age were not found to be significant, with the exception of the negative correlation between hair zinc and weight $(r=-0.464 ; P<0.047)$. Nevertheless, a multivariate linear regression equation accounted for about $24.6 \%$ of the variability of hair zinc values. In both children and adults, tests for sex differences in means and standard deviations using both raw score and residual values failed to reveal any significant differences. Similarly, no significant sex differences were observed between corresponding correlation coefficients. Results indicate that future studies utilizing hair must systematically or mathematically control for individual variation in zinc concentrations due to differences in age, weight, and height.

\section{REFERENCES AND NOTES}

1. Addink. N. W., and Frank, L. J.: Zinc content of hair from the head of carcinoma patients. Nature (Lond.). 193: 1190 (1962)

2. Brown, E. D., Chan, W., and Smith, J. C., Jr.: Vitamin A metabolism during the repletion of zinc deficient state. J. Nutr., 106: 563 (1976).

3. Creason. J. P., Hinners, T. A., Burngarner, J. E., and Pinkerton. C.: Trace elements in hair, as related to exposure in metropolitan New York. Clin. Chem.. 21: 603 (1975).

4. Eads. E. A., and Lambdin, C. E.: A survey of trace metals in human hair. Environ. Res., 6: 247 (1973).

5. Eatough, D. J., Christensen, J. J., lzatt, R. M., and Hartley, C.: Level of selected elements in human hair. In: A. C. Brown: The First Human Hair Symposium. (Medcom Press, Baltimore, MD, 1974).

6. Gentile, P. S.. Coleman, M., Hockman, A. J., and Trentalange, M. J.: (unpublished pilot study, 1977).

7. Halsted. J. A.: Events surrounding the original demonstration of human zinc deficiency. In: G. J. Brewer, A. S. Prasad: Zinc Metabolism: Current Aspects in Health and Disease. pp. 1-9 (Alan Liss, Inc., New York, 1976)

8. Hambidge, K. M., Hambidge, C., Jacobs, M., and Baum. J. D.: Low levels of zinc in hair, anorexia, poor growth, and hypogensia in children. Pediatr. Res., 6: 868 (1972)

9. Harrison, W. W., Yurachek, J. P., and Benson. C. A.: The determination of trace elements in human hair by atomic absorption spectroscopy. Clin. Chim. Acta. 23: 83 (1969).

10. Klevay, L. M.: Hair as biopsy material. I. Assessment of zinc nutriture. Am. J. Clin. Nutr., 23: 284 (1970).

11. Mahloudji. M., Reinhold, J. G., Haghshenass, M., Ronaghy, H. A., Spivey-Fox, M. R., and Halsted. J. A.: Combined zinc and iron compared with iron supplementation of diets of 6 to 12 years old village school children in southern Iran. Am. J. Clin. Nutr., 28: 721 (1975).

12. Nie. N. H., Hull, C. H., Jenkins, J. G., Steinbrenner, K., and Bent, D. H.: Statistical Package for the Social Sciences. (McGraw-Hill Book Co., New York. 1974)

13. Obrusnik, I., Gislason, J., McMillan, D. K., D'Auria, J., and Pate. B. D.: The variations of trace element concentrations in single human hairs. J. Forensic Sci., 17: 426 (1972).

14. Petering, H. G.. Yeager, D. W., and Witherup, S. O.: Trace metal content of hair. I. Zinc and copper content of human hair in relation to age and sex. Arch. Environ. Health, 23: 202 (1971).

15. Prasad, A. S., Miale, A.. Farid, Z.. Standstead, H. H.. Schulert, A. R., and Darby, W. J.: Biomedical studies on dwarfism, hypogonadism, and anemia. Arch. Intern. Med.. 111: 407 (1963).

16. Reinhold, J. G., Kfoury, G. A., Ghalarbor, M. A., and Bennett, J. C.: Zinc and copper concentrations in the hair of Iranian villagers. Am. J. Clin. Nutr., 18 : 294 (1966). 
17. Ronaghy, H. A., Reinhold, J. G., Mahloudji, M., Ghavami, P., Spivey-Fox, M. R., and Halsted, J. A.: Zinc supplementation of malnourished schoolboys in Iran: increased growth and other effects. Am. J. Clin. Nutr., 27: 112 (1974).

18. Smith, J. C., Brown, E. D., McDaniel, E. G., and Chan, W.: Alterations in vitamin A metabolism during zinc deficiency and food growth restriction. J. Nutr., 106: 569 (1976).

19. Smith, J. C., McDaniel, E. G., Fan, F. F., and Halsted, J. A.: Zinc: a trace element essential in vitamin A metabolism. Science (Wash. D. C.). 181: 954 (1973).

20. Solomons, N. W., Rosenfield, R. L., Jacob, R. A., and Sandstead, H. H.: Growth retardation and zinc nutrition. Pediatr. Res., 10: 923 (1976).

21. Strain, W. H., Pories, W. J., Flynn, A., and Hill, O. A.: Trace element nutriture and metabolism through head hair analysis. In: D. D. Hemphill: Trace

Copyright (C) 1981 International Pediatric Research Foundation, Inc. $0031-3998 / 81 / 1502-0123 \$ 02.00 / 0$
Substances in Environmental Health. Pp. 383-97 (University of Missouri Press, Columbia, MO, 1972)

22. Strain, W. H., Steadman, I. T., Landau, C. A., Berliner, W. P., and Pories, W. J. Analysis of zinc levels in hair for the diagnosis of zinc deficiency in man. $J$. Lab. Clin. Med., 68: 244 (1966).

23. Valković, V.: Trace Elements in Human Hair. (Garland STPM Press, New York. 1977).

24. Requests for reprints should be addressed to: Dr. Philip S. Gentile. Departmen of Chemistry, Fordham University, Bronx, NY (USA)

25. This research was supported by a Biomedical Research Support Grant RR 7150. to Fordham University.

26. Received for publication January 25, 1980.

27. Accepted for publication August 13,1980.

Printed in U.S.A. 